\title{
REVIEW
}

\section{Palliative care in COPD patients: is it only an end-of-life issue?}

\author{
Annalisa Carlucci*, Aldo Guerrieri ${ }^{*}$ and Stefano Nava ${ }^{\#}$
}

ABSTRACT: The presence of acute or chronic respiratory failure is often seen as a terminal phase of chronic obstructive pulmonary disease. A great variability in end-of-life practice is observed in these patients mainly because physicians are not always able to correctly predict survival. There is a need for a clear discussion about decision making earlier than when acute respiratory failure ensues. Indeed, a perceived poor quality of life does not necessarily correlate with a clear willingness to refuse invasive or noninvasive mechanical ventilation. It has been suggested to start palliative care earlier, together with curative and restorative care, when there is an increased intensity of symptoms. The patients eligible for palliative care are those complaining of breathlessness, pain, fatigue and depression, which in some studies accounted for a prevalence much higher than $\mathbf{5 0 \%}$. Among comfort measures for palliation, oxygen is frequently prescribed even when the criteria for long-term home oxygen therapy are not met; however, when compared with air, no benefits on dyspnoea have been found. The only drug with a proven effect on dyspnoea is morphine, but not when it is delivered with a nebuliser. Finally, noninvasive ventilation may be used only as a comfort measure for palliation to maximise comfort by minimising adverse effects.

KEYWORDS: Chronic obstructive pulmonary disease, ethics, noninvasive ventilation, palliative care

n Europe, attention to end-of-life care in the hospital setting, especially in the intensive care unit (ICU), has only increased in the last decade. A Medline search, conducted by the authors of this review in December 2011, found that more than 1,000 articles related to end-of-life care were published between 2001 and 2008 (fig. 1), compared with only 336 published before 2001. These studies were mainly published in North America, even though in more recent years the problem of end-of-life care has also gained a lot of attention in Europe and the rest of the world. Unfortunately, very few studies were performed in patients affected by chronic respiratory diseases, both in the phase of clinical stability or during an acute exacerbation of their diseases [1].

\section{THE DEFINITIONS OF END-OF-LIFE DECISIONS}

During the period at the end of life, potentially important decisions are needed. However, the correct definition of each possible intervention is extremely important and often a matter of debate among clinicians, bio-ethicists, religious figures and politicians. The following definitions are taken from the International Consensus Conference on challenges in end-of-life care in the ICU published in 2004 [2]

Withholding: a planned decision not to introduce therapies that are otherwise warranted (i.e. intubation, renal replacement therapy, increased doses of vasopressor infusions, surgery, transfusion, nutrition and hydration).

Withdrawal: discontinuation of treatments that have been started (i.e. decreasing inspiratory oxygen fraction to $21 \%$, extubation, turning off the ventilator and suspending the vasopressors).

Terminal sedation: pain and symptom treatment with the possible side-effect of shortening life.

Euthanasia: from the Greek words $e u$ and thanatos meaning "good death". It means that a doctor is intentionally killing a person who is suffering unbearably and hopelessly at the latter's voluntary, explicit, repeated, well-considered and informed request.

Physician-assisted suicide: means that a doctor is intentionally helping/assisting/co-operating in the suicide of a person who is suffering unbearably

\section{AFFILIATIONS}

*Respiratory Unit, Fondazione

S.Maugeri, IRCCS, Istituto Scientifico di Pavia, Pavia, and

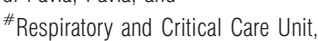
Sant'Orsola-Malpighi Hospital,

Bologna, Italy.

\section{CORRESPONDENCE}

S. Nava

Azienda Opedaliera Universitaria Sant'Orsola-Malpighi Hospital via Massarenti 9 40138 Bologna Italy E-mail: stefano.nava@aosp.bo.it 

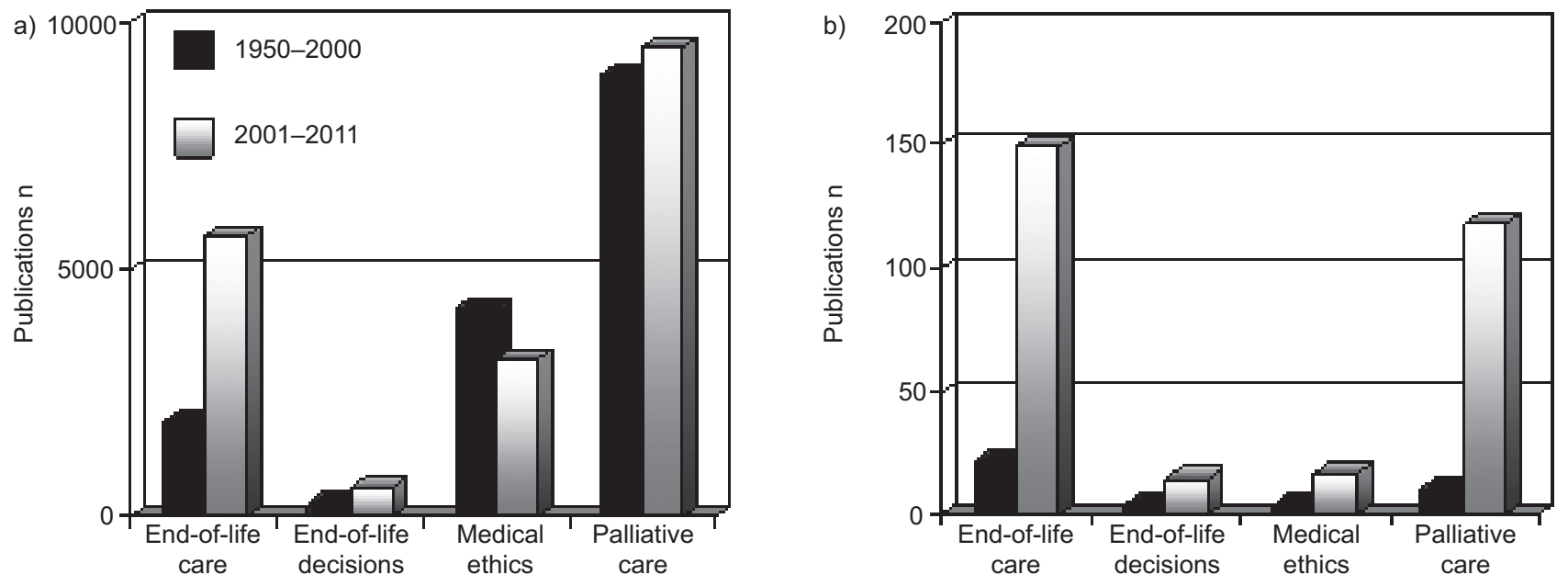

FIGURE 1. Number of publications in peer-reviewed journals in the field of end-of-life care in a) adults with all diseases, and b) adults with chronic obstructive pulmonary disease.

and hopelessly at the latter's voluntary, explicit, repeated, wellconsidered and informed request. These acts do not include withholding or withdrawing treatments although these may occur prior to physician-assisted suicide.

Cardiopulmonary resuscitation failure: defined as death despite the use of a ventilator or cardiac massage.

Brain death: documented cessation of cerebral function and meeting the criteria for brain death.

Palliative care: any interventions aimed to prevent and relieve suffering by controlling symptoms and providing other support to patients and families in order to maintain and improve their quality of living during all stages of chronic lifethreatening (or terminal) illness.

End-of-life care: is the care (comfort, supportive or symptom care) provided to a person in their final stages of life.

The Consensus Conference also highlighted the problem that many of the words used are imprecise or ambiguous, e.g. passive euthanasia and terminal weaning, and they may reflect specific religious orientations. For example, the termination of a continuous life-sustaining treatment, such as mechanical ventilation, is prohibited according to Jewish law or Halacha (followed mainly by Orthodox Jews), so that withdrawal is considered "passive euthanasia" [3]. A similar view was recently expressed by the Roman Catholic Church [4].

The overall incidence of these practices in Europe is only partially known, but there are important differences between countries or regions, reflecting the absence of a common strategy even within the European Community. For example, in 2002, in the Netherlands, the Euthanasia Act legalised euthanasia in a patient who is suffering unbearably with no prospect of improvement if all the due care criteria are fulfilled. Euthanasia is used most often in the Netherlands for patients with malignant disease. However, euthanasia was also performed in a patient with end-stage chronic obstructive pulmonary disease (COPD) [5] to end his or her life in dignity after having received every type of curative and palliative care available.
Indeed our societies are increasingly multicultural and multiracial, with a diversity of religious beliefs, whereas deficiencies in end-of-life care tend to be more pronounced in ethnic minority populations [6]. Recognising this pluralism is, therefore, fundamental to the provision of high- quality end-of-life care. Of interest, $<15 \%$ of ICU patients retain decision making capacity so it is impossible to discuss the decision with them, while rarely the patient's family are involved in the decision and when this is the case the relatives rate the communication with hospital staff as poor [7]. Concerning the problem of patients affected by chronic pulmonary disorders, the 2008 National COPD Audit identified that only $13 \%$ of units provide information to severe COPD patients when they are stable and $<25 \%$ of patients with oxygen dependence have discussed care with medical staff [8]. So, it was apparent that COPD patients typically receive little information, but information is essential for people making choices about their care. At last it was obvious that it was inappropriate to discuss these issues during exacerbation, but this is typically when such discussions occur [9].

\section{THE PATIENT WITH END-STAGE COPD}

The presence of acute or chronic respiratory failure is often seen as a terminal phase of this disease. Ethical problems about the treatment of acute exacerbation of end-stage COPD are increasingly topical, especially in respiratory units and the ICU. It is well known, in fact, that once one of these patients is intubated several factors may lead to a poor prognosis. Age, respiratory muscle weakness, hypercapnia, hypoxia, malnutrition, treatment with corticosteroids or other agents, haemodynamic instability and activity limits due to respiratory disorders may, for example, lead to difficulties in the weaning process [10]. A prospective, multicentre cohort study before the era of noninvasive ventilation (NIV) showed that patients with COPD admitted to an ICU for an acute exacerbation and who were aged $>65 \mathrm{yrs}$ had a mortality rate of $30 \%$, which doubled after $1 \mathrm{yr}$ to $60 \%$ [11]. A more recent retrospective study aiming to evaluate the long-term survival of patients being treated with NIV for the first time showed that survival at 1,2 and 5 yrs was $72 \%, 52 \%$ and $26 \%$, respectively [12]. The survival rate was also influenced by the need for readmission; 
those who required readmission had a $20 \%$ chance of survival at 5 yrs [13]. Once these chronically ill patients have recovered from the most acute phase of their critical illness they are still likely to require intensive nursing and/or physiotherapy for several weeks [14]. Although several studies showed that either invasive ventilation [15] or NIV [16] could be used to achieve an acceptable survival rate, we also know that once discharged, when this is feasible, most patients describe their quality of life as rather poor or poor after leaving the hospital, while in $\sim 20 \%$ of cases the last 6 months of life are spent inside a hospital or similar protected environment [17]. Indeed almost half of these patients die in hospital, most of them in the ICU, which is probably the worst environment to spend the last few days of life, due to the lack of privacy and the restricted policy of visiting from the relatives [18].

All this knowledge leads to the general perception that the outcome of COPD patients requiring mechanical ventilation is poor, thus, negatively influencing the choice to admit a patient in ICU. Moreover, a multicentre study in European ICUs showed that a chronic respiratory disease is a strong predictor of withholding and withdrawing therapies inversely, for example, for the use of cardiopulmonary resuscitation [19]. However, a great variability in the end-of-life practice was observed between countries. In a recent survey carried out in European respiratory intermediate care units, the prediction of a low probability of hospital survival or poor functional status following hospital discharge, as estimated by the attending physician, were the main reasons for withholding therapy [20]. However, physicians are not always able to correctly predict the survival of a patient. A study comparing mortality at 180 days as predicted by clinicians for patients with an exacerbation of COPD with the actual 180-day mortality found that clinicians are generally pessimistic about the survival prospects and have specific problems in identifying those with poor prognosis [21]. Table 1 illustrates the main obstacles and common beliefs that may determine ICU refusal in COPD patients. All these problems are unique features in the acute setting and highlight a need to approach a clear discussion about decision making earlier and in a stable phase. It must be considered that, in this context, perceived poor quality of life from the patient does not necessarily correlate with a clear willingness to refuse invasive mechanical ventilation in case of a severe acute respiratory failure. STAPLETON et al. [22] showed that in COPD patients whose severity at enrolment was defined only by the need for 24-h home oxygen, the health status as measured by the St George's Respiratory Questionnaire was not associated with end-of-life treatment preferences. This means that physicians should not assume that a poor health status is associated with a higher likelihood of refusing life-sustaining treatment. To avoid

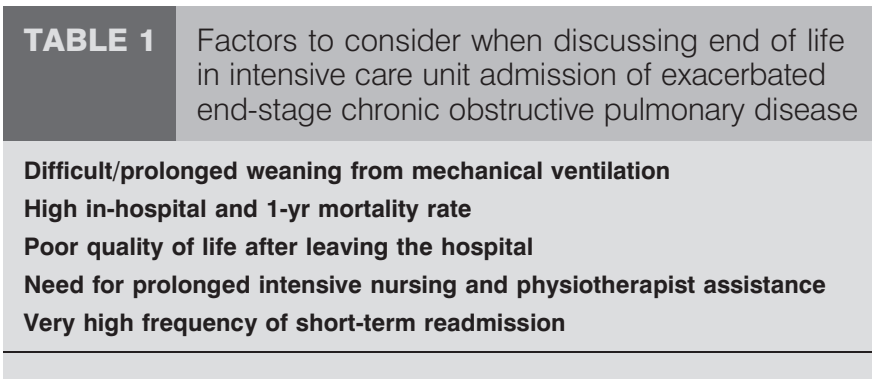

the possibility that only clinical judgment and "perception" by the physician could be the major drivers for treatment choice, a recent consensus on palliative care for patients with respiratory diseases recommended that palliative care include identification of, and respect for, the preferences of patients and families [23]. This highlights the need for clear patient-physician communication. However, surveys conducted on patients with oxygendependent severe COPD showed that only a small proportion of them $(32 \%)$ discuss the type of care they would want in the event they were too sick to take a decision with their physicians [24]. Patients complain that most physicians do not discuss how long the patients have to live, what dying might be like or spiritual issues [7]. Another important point is the identification of the timing of and when to raise the issue of end-of-life care. At present we do not have predictive parameters of short-term mortality in COPD patients. In a recent review, CURTIS [25] speculated that a patient with two or more of the following characteristics could be a good candidate for end-of-life discussion: forced expiratory volume in $1 \mathrm{~s}$ (FEV1) $<30 \%$ predicted; oxygen dependence; one or more hospital admissions in the previous year for an acute exacerbation of COPD; left heart failure or other comorbidities; weight loss or cachexia; decreased functional status; increasing dependence on others; and age $>70$ yrs. This method of identifying a patient who should be considered an "ideal" candidate for palliative care may be subject to criticism. We know, for example, that dyspnoea is not necessarily correlated to FEV1, so that a patient with an FEV $1>30 \%$ pred could complain of more symptoms than a patient with more severe airways obstruction [26]. However, it has been shown that COPD patients on long-term oxygen who have never previously required intensive care admission have a similar health status and cognitive function than COPD patients 6 months after discharge and recovery from an acute on chronic respiratory failure requiring mechanical ventilation [27]. Recently, a decision tree (CART) to identify patients at high-mortality risk in the next 5 yrs was proposed and validated [28]. This model takes into account five easily obtained parameters in clinical practice: age, FEV1, dyspnoea, physical activity and number of hospital admissions in the previous 2 yrs. The ability of the CART to predict mortality was tested in a validation cohort and it seems to be quite similar to other prediction scores, such as BODE (body mass index, degree of airway obstruction, dyspnoea, exercise capacity), but it also takes into account some new important clinical variables such as physical activity and previous hospitalisations, which could also strongly affect the mortality rate of the COPD patient.

Table 2 summarises the suggested definitions of end-stage COPD patients.

\section{WHEN SHOULD PALLIATION IN END-STAGE COPD BE STARTED?}

If the score could be used to identify patients with whom to discuss end-of-life treatments, it might not be so sensitive to identify patients who need mainly palliative support to relieve dyspnoea and other symptoms. For this reason, the aforementioned consensus [23] suggests to start palliative care earlier, together with curative and restorative care, when there is an increased intensity of the symptoms according to patient's and family's perception or when an acute exacerbation occurs. In other words, palliative care should be available at any point in 


\section{TABLE 2 Parameters suggested for evaluation of short-term mortality}

Two or more criteria [25]

FEV $1<30 \%$ predicted

Oxygen dependence

One or more hospital admissions in the previous year for an acute exacerbation of COPD

Left heart failure or other comorbidities

Weight loss or cachexia

Decreased functional status

Increasing dependence on others

Age $>70$ yrs
Decision tree [28]

\author{
Age $<75$ yrs \\ Dyspnoea degree \\ FEV $1<50 \%$ predicted
}

Physical activity (time spent walking during leisure time)

Number of exacerbations in the last 2 yrs

FEV1: forced expiratory volume in $1 \mathrm{~s}$; COPD: chronic obstructive pulmonary disease. Reproduced from [25] and modified from [28] with permission from the publishers.

time during the course of chronic respiratory disease when the patient becomes symptomatic. This means that it is necessary to define other criteria to identify the patient candidate for palliative care, since the goal of palliative care is also to identify and treat pathology-related symptoms. In fact, it is widely known that COPD patients complain of symptoms like breathlessness, pain, fatigue and depression that in some studies accounted for a prevalence much higher than 50\% [29]. Some studies compared the health status of COPD patient with patients affected by cancer. The latter patients have access to multidisciplinary palliative care focused on supporting the patient and their family to maintain a reasonable quality of life. In one of these studies the authors demonstrated that severe stable COPD (FEV $1<0.75 \mathrm{~L}$ and at least one previous episode of hypercapnic acute respiratory failure) had a significantly worse health status (physical, social and emotional) and worse activities of daily living than those with nonsmall cell lung cancer (NSCLC). Furthermore, they had symptoms of anxiety and depression to a significantly greater extent than the patients with NSCLC. Although nearly $90 \%$ of COPD patients had a Health Anxiety and Depression Scale score strongly suggestive for clinical depression and anxiety, only $4 \%$ of these patients were receiving pharmacological treatment [30]. Previous studies showed that depressive symptoms were significantly associated with refusal of life-sustaining treatment in oxygen-dependent COPD patients [22] and that symptom improvement after ad hoc pharmacological treatment could lead to a different preference about end-of-life treatment [31]. However, depressive symptoms were also found to be strong predictors of mortality in COPD patients (adjusted hazard risk 1.93) after correction for other risk variables [32]. Moreover, depression was not associated with severity of airflow obstruction and its decline at $1 \mathrm{yr}$, which means once more that the respiratory function severity alone cannot predict the best candidate for palliative care.

Unfortunately, the provision of palliative care for COPD patients in Europe is variable, and overall very small. In a survey performed in the UK, $\sim 21.5 \%$ of the respondents had formal policies in place for the care of patients with chronic respiratory disease nearing the end of life, but $87.9 \%$ of respondents had no formal process for initiating end-of-life discussions with those with terminal respiratory illness [33]. In the UK, patients with advanced non-malignant respiratory disease have less universal access to specialist palliative care services than those with malignant lung disease, and in the majority of hospitals there is no formalised approach to end-oflife care issues with patients with chronic lung disease.

In another UK survey, only $49 \%$ of units had a formal referral pathway for palliative care and only $13 \%$ had a policy of initiating end-of-life discussions with appropriate patients [34].

Indeed, an Irish study [35] showed that key barriers towards the delivery of palliative care for COPD patients included the reluctance to negotiate end-of-life decisions and a perceived lack of understanding among patients and carers regarding the illness trajectory. Consequently, the delivery of palliative care was viewed as a specialist role rather than an integral component of care.

\section{THE INTERVENTIONS}

Table 3 summarises the potential palliative treatment for endstage COPD patients.

Quality of life measurement is an important aspect of palliative care, given that maximising this item is the main aim of this type of care. A large variety of quality of life measurement instruments are appropriate for use in palliative care, but unfortunately most have not been adequately evaluated so the effectiveness of the pharmacological and non-pharmacological interventions is not always easy to assess [36]. Palliative care may be considered as a set of interventions aimed to recognise and treat symptoms; therefore, encompassing all the actions needed to treat fatigue, breathlessness and pain, and the other complains that the patients may experience. The official American Thoracic Society (ATS) Clinical Policy Statement on Palliative Care [23] stated that treatment should focus on both the psychological and physical components of dyspnoea, and rely on visual or analogue dyspnoea scales to assess the severity of symptoms and effects of treatment. Therefore, pharmacological treatments proposed for COPD at different stages of the pathology are mainly aimed to improve dyspnoea, exercise tolerance and possibly rate of exacerbation.

\section{Rehabilitation}

Clinical guidelines for the management of patients with COPD have also made clear recommendations about non-pharmacological treatment, such as rehabilitation, in stable COPD based 


\begin{tabular}{|c|c|c|}
\hline TABLE 3 & $\begin{array}{l}\text { o be considered for } t \\
\text { stage chronic obstru } \\
\text { e in a chronic and ac }\end{array}$ & $\begin{array}{l}\text { atment of symptoms } \\
\text { ive pulmonary } \\
\text { te setting }\end{array}$ \\
\hline Symptom & Chronic setting & Acute setting \\
\hline $\begin{array}{l}\text { Dyspnoea/ } \\
\text { breathlessness }\end{array}$ & $\begin{array}{l}\text { Pharmacological therapy } \\
\text { Physical rehabilitation } \\
\text { Oxygen therapy } \\
\text { Noninvasive ventilation }\end{array}$ & $\begin{array}{c}\text { Pharmacological therapy } \\
\text { Oxygen therapy } \\
\text { Noninvasive ventilation } \\
\text { Opioids }\end{array}$ \\
\hline $\begin{array}{l}\text { Anxiety and } \\
\text { depression }\end{array}$ & $\begin{array}{l}\text { Physical rehabilitation } \\
\text { Pharmacological therapy }\end{array}$ & $\begin{array}{c}\text { Pharmacological therapy } \\
\text { Sedation }\end{array}$ \\
\hline
\end{tabular}

on high levels of research evidence. A rehabilitation programme significantly improves exercise capacity and healthrelated quality of life, and reduces the perceived intensity of breathlessness and decreases anxiety and depression associated with COPD with a level A of evidence [37].

\section{Noninvasive ventilation}

On the same line, even if unable to demonstrate improved survival in chronic COPD, long-term NIV was able to, according to several studies, improve quality of life and dyspnoea measured by the Medical Research Council scale [38, 39]. However, a pilot study [40] and a recent document about the application of NIV in different settings [41] recognised an important role of NIV as a palliative tool, merely aimed to treat dyspnoea when acute respiratory distress or failure ensues [42].

The need for mechanical support is theoretically the main intervention when an organ is failing beyond a point in which any pharmacological intervention is ineffective or partially effective. This is true for the kidney, lung and even the heart. The problem is understanding in the clinical practice as to when mechanical support may be futile.

Failure of weaning from invasive mechanical ventilation is one of the major clinical problems in COPD patients. In one study these "chronically critically ill" patients, representing only 3\% of the total number of patients admitted to the ICU, used almost $40 \%$ of the total patient days of care [17]. The manner in which this relatively small population cuts into hospital costs has drawn the attention of experts in the field, thus, SENEFF et al. [11] have openly stated that, "there is some level of costs of acute care that is beyond our society's economic capacity". Does this mean that a patient with advanced COPD always "deserves" an end-of-life care decision? The general perception is that the outcome of COPD patients requiring mechanical ventilation is poor, despite several studies in which invasive ventilation [20] or NIV [21] was employed to demonstrate an acceptable survival rate [43].

With the introduction of NIV to treat acute respiratory failure of different aetiologies 20 yrs ago, classical outcome measures such as hospital mortality, need for endotracheal intubation, complications of invasive ventilation and length of hospital stay have been drastically improved. The feasibility and usefulness of NIV in the palliative care of patients with acute respiratory failure near the end of their lives is still not well demonstrated [41]. Frequently, NIV is also used for those patients with terminal diseases to help alleviate respiratory distress and attempt to provide some additional time, for example to say goodbye to their relatives and friends or to solve some administration issues, but most of the clinicians are unclear about the goals of care. For example, it has been highlighted that NIV may be inappropriate in this context because of an increased use of medical resources, prolongation of the dying process and intensification of suffering [42]. The Society of Critical Care Medicine suggested an approach based on explicating the goal of care, emphasising the importance of information and communication among patients, family and clinicians. They reviewed three potential goals and alternative clinical scenarios. First, life support without limits, whereby the primary goal is to assist ventilation and reduce the risk of intubation and mortality, eventually restoring health. The aim is to restore health without using endotracheal intubation and without causing unacceptable discomfort [42]. Secondly, life support with limit, whereby the goal is to restore health without using endotracheal intubation and the response to failure is mainly to palliate symptoms without using NIV. Finally, comfort measures for palliation to maximise comfort and minimise adverse effects [42]. In a multicentre, randomised controlled trial comparing oxygen therapy versus NIV in end-stage solid cancer patients, this latter procedure reduced dyspnoea and respiratory rate faster, while less morphine was needed, preserving the patient's mental integrity [44].

So there is a need to facilitate the decision concerning NIV or any other form of mechanical ventilation. When the patients are well informed they are generally satisfied with the decision that has been made and don't change their mind in the meantime [45].

Therefore, the decision to commence mechanical ventilation in end-stage COPD needs the active participation of the patient. Physicians and educators should target patients with COPD to improve patients' education about diagnosis and the disease process together with the explanation of the treatments, prognosis, what dying might be like and advance care planning. To address these issues DALES et al. [45] developed and tested an aid to assist patients with decisions about mechanical ventilation. A scenario-based decision aid was developed, consisting of an audiocassette and a booklet describing intubation and mechanical ventilation and its possible outcomes. The authors used a probability trade-off technique to elicit the patients' preferences and a decisional conflict scale to evaluate satisfaction. With the assistance of the decision aid, all patients (10 male and 10 females) reached a decision. Two males and all 10 females declined mechanical ventilation. Mean decisional conflict was low (2.2 out of a maximum of 5). At $1 \mathrm{yr}$, only two (11\%) patients had changed their decisions. The agreement between physicians and patients was $65 \%$; between next-of-kin and patients, however, there was uniform disagreement. From this study it maybe concluded that when discussed and explained in detail, an end-of-life decision is stable in time while the patients achieve satisfaction and confidence. Proxy decisions were incongruent, especially when made by family members; however, the strong sex effect suggested a call for further investigation.

\section{Oxygen}

Among comfort measures for palliation, oxygen is frequently prescribed even when the criteria for long-term home oxygen therapy is not met because of the sensation of breathlessness, 
which is a devastating symptom and causes distress for the patient and the caregivers [46]. However, in COPD patients, treatment with oxygen compared with air has been found to have a small beneficial effect on dyspnoea [47]; oxygen is not effective in reducing the sensation of dyspnoea in cancer patients, even during exercise [48, 49].

\section{Opioids}

The only drugs with a proven effect on dyspnoea are opioids. Opioid receptors are found in high densities in the brain stem and may exert an inhibitory influence on respiratory drive mainly mediated by mu receptors. Moreover, opioids have anxiolytic properties further diminishing dyspnoea. Indeed, they may reduce effects of arterial carbon dioxide and oxygen levels on ventilation, and reduce oxygen consumption at rest [50]. However, most of the studies on the effects of opioids on dyspnoea were performed in patients with end-stage cancer. For example, a systematic review by JenNings et al. [51] supports the continued use of oral and parenteral opioids to treat dyspnoea in patients with advanced disease. There are insufficient data from the meta-analysis to conclude whether nebulised opioids are effective, but the results from included studies that did not contribute to the meta-analysis suggest that they are no better than nebulised normal saline. Of particular interest, the results of the subgroup analysis of the COPD studies were essentially similar to the results of the main analysis. More recently, and after the publication of the meta-analysis, a randomised, double-blind placebo-controlled trial [52] was performed in patients with refractory dyspnoea, the large majority of patients being affected by COPD. The patients were randomised to 4 days of $20 \mathrm{mg}$ oral morphine with sustained release followed by 4 days of identically formulated placebo, or vice versa. Participants reported significantly different dyspnoea scores, both in the morning and in the evening, when treated with morphine. During the period in which they were taking morphine, participants also reported better sleep but also distressing constipation in spite of using laxatives. JUAN et al. [53] investigated in an open label clinical study whether epidural methadone perfusion at the thoracic level can mitigate dyspnoea in patients with advanced emphysema. They showed that this method effectively palliates dyspnoea and improves exercise capacity and quality of life in these patients, without deterioration in respiratory control or lung function. The authors concluded that modulation of spinal cord afferent signalling is an appropriate novel target for dyspnoea control in chronic respiratory disease.

However, the Global Initiative for Chronic Lung Disease (GOLD) guidelines have specifically stated that opioids are contraindicated in COPD management due to potential respiratory depression and worsening hypercapnia. However, several investigations have found no evidence that the appropriate use of these drugs hastens death [54-56], despite the "principle of double effect" addressing the potential for harm by use of opioids in palliative care [57]. As stated in the ATS Clinical Policy Statement on Palliative Care [23], this principle holds that relief of suffering is adequate justification for the use of opioids to control dyspnoea or pain, and that hastening death by the use of opioids, if it occurs, is morally acceptable provided that the intent of the physician or nurse is confined to relief of dyspnoea. Consistent with this principle, healthcare providers should titrate the dose of opioid to its effect in relieving dyspnoea, i.e. dosing interval and quantity based on frequent symptom assessment using a dyspnoea scale or physiological manifestations of dyspnoea. "Morphinophobia" among clinicians and the general population, however, leads to the inappropriate management of pain and dyspnoea, at least in some countries [58].

\section{Management of secretions}

Mucolytics and occasional courses of antibiotics may be useful adjuncts in decreasing dyspnoea for patients with excess tenacious secretions [59]. No data about the management of airway secretion during end-stage chronic respiratory illness are available. During a mild acute exacerbation the use of a mechanical aid dedicated to secretion removal is effective in avoiding further deterioration and the need for ventilator support either invasively or noninvasively [60]. In overt hypercapnic respiratory failure needing ventilator support, ANTONAGLIA et al. [61] showed that two daily sessions of intrapulmonary percussive ventilation through a mouthpiece with a helmet during NIV could decrease the duration of ventilator treatment and ICU stay. These may not necessarily be the outcomes of end-of-life care, but the study demonstrated a feasibility of this mucus clearance strategy in COPD patients.

In conclusion, a COPD patient with a documented progressive decline of respiratory function and health status should be taken into account with the aim to recognise all clinically evident symptoms, treat them in the best way and continuously discuss the patient's wishes about end-of life treatment.

\section{STATEMENT OF INTEREST}

None declared.

\section{REFERENCES}

1 Goodridge DM, Marciniuk DD, Brooks D, et al. End-of-life care for person with advanced chronic obstructive pulmonary disease. Can Respir J 2009; 16: 51-53.

2 Lambertus JC, Thijs G, Antonelli M, et al. Challenges in end-of-life care in the ICU. Statement of the 5th International Consensus Conference. Intensive Care Med 2004; 30: 770-784.

3 Keenan SP, Mawdsley C, Plotkin D, et al. Withdrawal of life support: how the family feels, and why. J Palliat Care 2000; 16: Suppl., S40-S44.

4 Ruini C. Prolusione del Cardinale Presidente. Conferenza Episcopale Italiana Consiglio Permanente [Prolusion President of Cardinal. Final Communique of the Permanent Episcopal Council]. Rome, January 22-25, 2007.

5 Janssen DJ, Alsemgeest TP, Widdershoven GA, et al. The last wish of a patient with end stage chronic obstructive pulmonary disease. BMJ 2008; 337: a2701.

6 Borum ML, Lynn J, Zhong Z. The effects of patient race on outcomes in seriously ill patients in SUPPORT: an overview of economic impact, medical intervention, and end-of-life decisions. J Am Geriatr Soc 2000; 48: Suppl. 5, S194-S198.

7 Curtis JR, Engelberg RA, Nielsen EL, et al. Patient-physician communication about end-of-life care for patients with severe COPD. Eur Respir J 2004; 24: 200-205.

8 Royal College of Physicians of London, British Thoracic Society, British Lung Foundation. Report of the National Chronic Obstructive Pulmonary Disease Audit 2008: clinical audit of COPD exacerbations admitted to acute NHS units across the UK. www.rcplondon.ac.uk/sites/default/files/report-of-the-nationalcopd-audit-2008-clinical-audit-of-copd-exacerbations-admitted-toacute-nhs-units-across-the-uk.pdf Date last accessed: 14 June, 2010. 
9 Department of Health. End of life care strategy - promoting high quality care for all adults at the end of life. Publications Policy and Guidance/DH-086277/; 2008. www.dh.gov.uk/en/Publicationsand statistics/Publications/PublicationsPolicyAndGuidance/DH_086277 Date last accessed: August, 2012.

10 Nava S, Rubini F. Weaning through noninvasive mechanical ventilation. In: Hill N, Levy MM, eds. Ventilatory Management Strategies for Critical Care. New York, Dekker Inc., 2001; pp. 579-609.

11 Seneff MG, Wagner DP, Wagner RP, et al. Hospital and 1-year survival of patients admitted to intensive care units with acute exacerbation of chronic obstructive pulmonary disease. JAMA 1995; 274: 1852-1857.

12 Chung LP, Winship P, Phung S, et al. Five-year outcome in COPD patients after their first episode of acute exacerbation treated with non-invasive ventilation. Respirology 2010; 15: 1084-1091.

13 Soler Cataluña JJ, Martínez García MA, Román Sánchez P, et al. Severe acute exacerbations and mortality in patients with chronic obstructive pulmonary disease. Thorax 2005; 60: 925-931.

14 Nava S. Rehabilitation of patients admitted to a respiratory intensive care unit. Arch Phys Med Rehabil 1998; 79: 849-854.

15 Breen D, Churches T, Hawker F, et al. Acute respiratory failure secondary to chronic obstructive pulmonary disease treated in the intensive care unit: a long term follow up study. Thorax 2002; 57: 29-33.

16 Lightowler JV, Wedzicha JA, Elliott MW, et al. Non-invasive positive pressure ventilation to treat respiratory failure resulting from exacerbations of chronic obstructive pulmonary disease: Cochrane systematic review and meta-analysis. BMJ 2003; 326: 185-190.

17 Lynn J, Ely EW, Zhong Z, et al. Living and dying with chronic obstructive pulmonary disease. J Am Geriatr Soc 2000; 48: Suppl. 5, S91-S100.

18 Vitacea M, Grassi M, Barbano L, et al. Last 3 months of life in home-ventilated patients: the family perception. Eur Respir J 2010; 35: 1064-1071.

19 Sprung CL, Cohen SL, Sjokvist P, et al. End-of-life practices in European intensive care units. The Ethicus Study. JAMA 2003; 290: 790-797.

20 Nava S, Sturani C, Hartl S, et al. End-of-life decision-making in respiratory intermediate care units: a European survey. Eur Respir J 2007; 30: 156-164.

21 Wildman MJ, Sanderson C, Groves J, et al. Implications of prognostic pessimism in patients with chronic obstructive pulmonary disease (COPD) or asthma admitted to intensive care in the UK within the COPD and asthma outcome study (CAOS): multicentre observational cohort study. BMJ 2007; 335: 1132.

22 Stapleton RD, Nielsen EL, Engelberg RA, et al. Association of depression and life-sustaining treatment preferences in patients with COPD. Chest 2005; 127: 328-334.

23 Lanken PN, Terry PB, Delisser HM, et al. An official American Thoracic Society clinical policy statement: palliative care for patients with respiratory diseases and critical illnesses. Am J Respir Crit Care Med 2008; 177: 912-927.

24 Knauft E, Nielsen EL, Engelberg RA, et al. Barriers and facilitators to end-of-life care communication for patients with COPD. Chest 2005; 127: 2188-2196.

25 Curtis JR. Palliative and end-of-life care for patients with severe COPD. Eur Respir J 2008; 32: 796-803.

26 National Emphysema Treatment Trial Research Group. A randomized trial comparing lung-volume-reduction surgery with medical therapy for severe emphysema. N Engl J Med 2003; 348: 2059-2073.

27 Ambrosino N, Bruletti G, Scala V, et al. Cognitive and perceived health status in patient with chronic obstructive pulmonary disease surviving acute on chronic respiratory failure: a controlled study. Intensive Care Med 2002; 28: 170-177.
28 Esteban C, Arostegui I, Moraza J, et al. Development of a decision tree to assess the severity and prognosis of stable COPD. Eur Respir J 2011; 38: 1294-1300.

29 Solano JP, Gomes B, Higginson IJ. A comparison of symptom prevalence in far advanced cancer, AIDS, heart disease, chronic obstructive pulmonary disease and renal disease. J Pain Symptom Manage 2006; 31: 58-69.

30 Gore JM, Brophy CJ, Greenstone MA. How well do we care for patients with end stage chronic obstructive pulmonary disease (COPD)? A comparison of palliative care and quality of life in COPD and lung cancer. Thorax 2000; 55: 1000-1006.

31 Rosenfeld KE, Wenger NS, Phillips RS, et al. Factors associated with change in resuscitation preference of seriously ill patients. The SUPPORT Investigators. Study to Understand Prognoses and Preferences for Outcomes and Risks of Treatments. Arch Intern Med 1996; 156: 1558-1564.

$32 \mathrm{Ng}$ TP, Niti M, Tan WC, et al. Depressive symptoms and chronic obstructive pulmonary disease: effect on mortality, hospital readmission, symptom burden, functional status, and quality of life. Arch Intern Med 2007; 167: 60-67.

33 Partridge MR, Khatri A, Sutton L, et al. Palliative care services for those with chronic lung disease. Chron Respir Dis 2009; 6: 13-17.

34 Buxton KL, Stone RA, Buckingham RJ, et al. Current and planned palliative care service provision for chronic obstructive pulmonary disease patients in 239 UK hospital units: comparison with the gold standards framework. Palliat Med 2010; 24: 480-485.

35 Spence A, Hasson F, Waldron M, et al. Professionals delivering palliative care to people with COPD: qualitative study. Palliat Med 2009; 23: 126-131.

36 Albers G, Echteld MA, de Vet HC, et al. Evaluation of quality-oflife measures for use in palliative care: a systematic review. Palliat Med 2010; 24: 17-37.

37 Global Initiative for Chronic Obstructive Lung Disease (GOLD). Global strategy for the diagnosis, management and prevention of chronic obstructive pulmonary disease. Revised 2011. www.gold copd.org/uploads/users/files/GOLD_Report_2011_Feb21.pdf

38 Clini E, Sturani C, Rossi A, et al. The Italian multicentre study on noninvasive ventilation in chronic obstructive pulmonary disease patients. Eur Respir J 2002; 20: 529-538.

39 Dreher M, Ekkernkamp E, Walterspacher S, et al. Noninvasive ventilation in COPD: impact of inspiratory pressure levels on sleep quality. Chest 2011; 140: 939-945.

40 Cuomo A, Delmastro M, Ceriana P, et al. Noninvasive mechanical ventilation as a palliative treatment of acute respiratory failure in patients with end-stage solid cancer. Palliat Med 2004; 18: 602.

41 Scala R, Nava S. NIV and palliative care. Eur Respir Monogr 2008; 41: 287-306.

42 Curtis JR, Mitchell M, Levy M, et al. Noninvasive positive pressure ventilation in critical and palliative care setting: understanding the goals of therapy. Crit Care Med 2007; 35: 932-939.

43 Chandra D, Stamm JA, Taylor B, et al. Outcomes on noninvasive ventilation for acute exacerbations of chronic obstructive pulmonary disease in the United States, 1998-2008. Am J Respir Crit Care Med 2012; 185: 152-159.

44 Nava S, Esquinas A, Ferrer M, et al. Multicenter randomised study of the use of non-invasive ventilation vs oxygen therapy $\left(\mathrm{O}_{2}\right)$ in reducing dsypnea in end-stage solid cancer patients with respiratory failure and distress. Eur Respir J 2007; 30: Suppl. 51, P1270.

45 Dales RE, O'Connor A, Hebert $\mathrm{P}$, et al. Intubation and mechanical ventilation for COPD. Chest 1999; 116: 792-800.

46 Caprio A, Munn L. Pain, dyspnea and the quality of dying in longterm care. J Am Geriatr Soc 2008; 56: 683-688.

47 Garrod R, Wedzicha JA. Supplemental oxygen during pulmonary rehabilitation in patient with COPD with exercise hypoxaemia. Thorax 2000; 55: 539-543. 
48 Del Fabbro E, Dalal S, Bruera E. Symptom control in palliative care. Palliat Med 2003; 17: 659-663.

49 Uronis HE, Abernethy AP. Oxygen for relief of dyspnoea in mildly- or non-hypoxaemic patients with cancer; a systematic review and meta-analysis. Br J Cancer 2008; 98: 294-299.

50 Peiffer C, Poline JB, Thivard L, et al. Neural substrates for the perception of acutely induced dyspnea. Am J Respir Crit Care Med 2001; 163: 951-957.

51 Jennings A-L, Davies AN, Higgins JPT, et al. A systematic review of the use of opioids in the management of dyspnoea. Thorax 2002; 57: 939-944.

52 Abernethy AP, Currow DC, Frith P, et al. Randomised, double blind, placebo controlled crossover trial of sustained release morphine for the management of refractory dyspnoea. BMJ 2003; 327: 523-528.

53 Juan G, Ramón M, Valia JC, et al. Palliative treatment of dyspnea with epidural methadone in advanced emphysema. Chest 2005; 128: 3322-3328.

54 Chan JD, Treece PD, Engelberg RA, et al. Narcotic and benzodiazepine use after withdrawal of life support: association with time to death? Chest 2004; 126: 286-293.
55 Bercovitch M, Waller A, Adunsky A. High dose morphine use in the hospice setting: a database survey of patient characteristics and effect on life expectancy. Cancer 1999; 86: 871-877.

56 Sykes N, Thorns A. The use of opioids and sedatives at the end of life. Lancet Oncol 2003; 4: 312-318.

57 Sulmasy DP, Pellegrino ED. The rule of double effect: clearing up the double talk. Arch Intern Med 1999; 159: 545-550.

58 Verloo H, Mpinga EK, Ferreira M, et al. Morphinofobia: the situation among the general population and health care professionals in North-Eastern Portugal. BMC Palliative Care 2010; 9: 15.

59 Aquilina R, Bergero F, Noceti P, et al. Double blind study with neltenexine vs. placebo in patients affected by acute and chronic lung diseases. Minerva Pneumologica 2001; 40: 77-84.

60 Vargas F, Bui HN, Boyer A, et al. Intrapulmonary percussive ventilation in acute exacerbations of COPD patients with mild respiratory acidosis: a randomized controlled trial [ISRCTN17802078]. Crit Care 2005; 9: R382-R389.

61 Antonaglia V, Lucangelo U, Zin WA, et al. Intrapulmonary percussive ventilation improves the outcome of patients with acute exacerbation of chronic obstructive pulmonary disease using a helmet. Crit Care Med 2006; 34: 2940-2945. 